\title{
A new genus of an Oriental Rhyparochromini (Heteroptera: Rhyparochromidae) to place Caridops albomarginatus (Scott, 1874) and the use of SDM to test an extra-Palaearctic record
}

\author{
Pablo M. Dellapé ${ }^{\text {a, }}$, María Cecilia Melo ${ }^{\mathrm{a}}$, Sara I. Montemayor ${ }^{\mathrm{a}}$, Előd Kondorosy ${ }^{\mathrm{b}}$ \\ ${ }^{a}$ Universidad Nacional de La Plata, CONICET, División Entomología, Museo de La Plata, Paseo \\ del Bosque s/n B1900FWA, La Plata, Buenos Aires, Argentina. \\ ${ }^{b}$ Dept. of Animal Science, Georgikon Faculty, University of Pannonia, Deák F. u. 16, H-8360 \\ Keszthely, Hungary. \\ *Corresponding author. pdellape@ffcnym.unlp.edu.ar (P. M. Dellapé)
}

\begin{abstract}
The new genus Scudderocoris (Heteroptera: Rhyparochromidae: Rhyparochromini) is established to accommodate Caridops albomarginatus, a species known from China, Japan, and South Korea: Scudderocoris albomarginatus (Scott, 1874) comb. nov. The species is redescribed and photographs of the adult male and its genitalia are provided.

The finding of a male specimen labeled from South America is intriguing. To evaluate if this species could find suitable climatic conditions in the Neotropics, we performed a Species Distributional Model (SDM), based on native distribution records, and compared the bioclimatic variables between the native range and the area where the specimen was supposedly collected. Our conclusion that the specimen was mislabeled, shows that SDM can be a useful tool in detecting collection label biases.
\end{abstract}

Key words: Scudderocoris, new genus, Rhyparochromidae, Rhyparochrominae, Scudderocoris albomarginatus comb. nov., Species Distributional Modeling. 


\section{Introduction}

The Rhyparochromidae, with more than 2,000 species, is the most diverse group of the Lygaeoidea (Henry et al., 2015). It is divided into two subfamilies: Plinthisinae and Rhyparochrominae, the latter of which includes 14 tribes (Henry, 1997). The Rhyparochromini, one of the largest tribes, includes more than 370 species and is most diverse in the Old World tropics and subtropics, with an extensive Palaearctic fauna (Cassis and Gross, 2002).

In the Western Hemisphere, the tribe is represented by three genera and seven species from the Nearctic Region (Ashlock and Slater, 1988), and only three species from the Neotropical Region: Laschnesthus singalensis (Dohrn, 1860) native of Africa and Asia, that was recorded in Sinaloa, Mexico (Slater \& Lattin 1965); and Elasmolomus squalidus (Gmelin, 1790) (=Elasmolomus sordidus (Fabricius, 1787)) and Dieuches armatipes (Walker, 1872), that are native from the Old World and have been reported as a serious pest of peanuts in Africa and the Oriental Region (Slater, 1972; Henry and Froeschner, 1993; Henry et al., 2015). Elasmolomus squalidus is well established in Piracicaba (São Paulo, Brazil) (Slater, 1972), and Dieuches armatipes have been recorded from Dominican Republic, Grand Cayman Island, Jamaica and St. Kitts (Henry and Froeschner, 1993) and from St. Croix and Cayman Brac (Brambila and Halbert, 2004). Henry and Froeschner (1993) suggested that both species were introduced in international commerce.

While visiting the entomological collection of the Museum Nationale d'Histoire Naturelle $(\mathrm{MNHN})$ in Paris, the senior author discovered a male rhyparochromid labeled from the frontier between Venezuela and Brazil, that was surprisingly identified as Caridops albomarginatus (Scott, 1874). This Oriental rhyparochromine was described from Japan and later reported from Ryukyu Islands, China, and South Korea (Slater, 1964; Miyamoto, 1970; Zheng and Zhou, 1981; Cui et al., 1999; Hayashi, 2002; Byun et al., 2009; Hong et al., 2012; Lim et al., 2013). For a complete list of the literature see Lygaeoidea Species File Online (Dellapé and Henry).

After a careful examination of the species we consider that $C$. albomarginatus is not congeneric with the type species of Caridops Bergroth, 1894, C. gibbus Bergroth, 1894; moreover, it also does not fit into any known genus in the tribe. Accordingly, we establish the new genus Scudderocoris for this species. Scudderocoris albomarginatus comb. nov. is redescribed; photographs of the male and its genitalia are also provided. 
The finding of this species labeled from South America is intriguing, so with the aim of evaluating if this species could find suitable climatic conditions in the Neotropics, we performed a Species Distributional Model (SDM) based on the native records and then transferred it worldwide. We also compared the bioclimatic variables between the native range and the area where the specimen was supposedly collected. Recently, species distributional modeling has become an increasingly important tool to address several issues in ecology, biogeography, evolution, conservation biology, and climate change research (Guisan and Thuiller, 2005). These modeling techniques have been widely used for various ecological and evolutionary applications. Here we test SDM as a tool to help detect collection label biases.

\section{Material and methods}

\subsection{Morphological analysis}

Color images were captured using a digital camera (Micrometrics 391CU, $3.2 \mathrm{~m}$ ) mounted on a Nikon SMZ1000 stereomicroscope. Multiple focal planes were merged using Micrometrics SE Premium 4 software. The genital structures were dissected under a stereomicroscope, cleared in a $10 \% \mathrm{KOH}$ aqueous solution, washed in distilled water, and preserved in a vial with glycerin. All measurements are in millimeters. The terminology used for the description of the hind wing is that of Slater \& Hurlbutt (1957). Acronyms used are: BMNH: British Museum of Natural History; MNHN: Museum nationale d'Histoire Naturelle; NHMW: Naturhistorisches Museum Wien; IRSN: Institute Royal des Sciences Naturelles de Belgique.

\subsection{Species distributional modeling and climatic profile}

The SDM was performed using Maxent v3.3.3k (Phillips et al., 2006), with 37 occurrence records (6 from South Korea, 22 from Japan, and 9 from China) compiled from the literature after filtering duplicate and doubtful information (Data available as Supp. file 1). To train the model we used the 11 minimally correlated bioclimatic variables available at WorldClim database with a 2.5 arc min resolution (Bio 2, 3, 5, 6, 7, 8, 9, 12, 13, 15 and 17). The model was tuned using 4-fold cross-validation and modifying two parameters, i.e., feature class (L-H-LQ-Q) and regularization multiplier (1, 1.5, 2, 2.5 and 3) following the indices proposed by Radosavljevic and Anderson (2014) (average Evaluation AUC, difference between Calibration AUC and Evaluation AUC and Omission rate). After these experiments, we reached an optimal 
level of model complexity using a hinge feature class and a regularization multiplier of 1. For model validation we used the null models approach (Raes and Ter Steege, 2007). Ninety-nine null models based on 37 randomly distributed occurrences and on the same variables as the ones used to build the real model were used. If the AUC of the real models fell in or above the highest $5 \%$ of the AUCs of the null models, the real models were considered statistically significantly better than random. The final model was converted into a binary presence/absence map, based on the "minimum training presence logistic threshold" that indicates values above which the climate conditions are suitable for the survival of the modeled species.

Raw environmental data were extracted for the nineteen WorldClim variables from all the occurrences in the native range of distribution and from the Brazilian-Venezuelan frontier. With this information, we built boxplots to identify the climatic variables with similar values between the two considered areas.

\section{Results}

\subsection{Taxonomy}

Scudderocoris Dellapé, Melo \& Kondorosy gen. nov.

http://lsid.speciesfile.org/urn:lsid:Lygaeoidea.speciesfile.org:TaxonName:492169

Type species: Gyndes albomarginatus Scott, 1874

Description. Head (Fig. 1A-C) coriaceous, with many small punctures. Juga with a ridge. Buccular juncture broadly U-shaped, occupying most of ventral region of head. Eyes subpedunculate. Clypeus longer than juga. Scape surpassing apex of head. Thorax (Figs. 1A, B). Pronotum coriaceous, with fine recumbent pubescence and long erect setae. Collar distinct, coarsely punctate, not delimited posteriorly by a demarked groove, ventral region with a smooth flange anteriorly and strongly punctate. Anterior pronotal lobe finely punctate, transverse impression and posterior lobe strongly punctate; anterior pronotal lobe globose with lateral margins rounded, lateral margins of posterior lobe with posterior $2 / 3$ carinate, humeral angles roundly projecting posteriorly over wing insertion (Fig. 1A); posterior margin at middle straight. Mesepimeron enclosed. Evaporatorium extensive. Prosternum transversely rugose and micropunctate. Clavus with three complete rows of punctures. Hind wing showing a generalized 
pattern as in other members of the tribe (Fig. 2). Male protibia spined. Abdomen. Finely punctate and subshiny. Inner laterotergites on segments IV, V, and VI not visible. Stridulitrum on abdominal segments II-IV, plectrum on inner surface of metafemur formed by a field of small tubercles.

Etymology. This new genus is named in honor of our colleague Dr. Geoffrey G. E. Scudder, who has published numerous important papers on Lygaeoidea.

Scudderocoris albomarginatus (Scott, 1874) comb. nov.

http://sid.speciesfile.org/urn:lsid:Lygaeoidea.speciesfile.org:TaxonName:492170

Gyndes albomarginatus Scott 1874 (Ann. Mag. nat. Hist. 4, 14, 437-438).

Material examined. Female Lectotype [glue to card] (BMNH); Male, Amérique du Sud, from frontier Vénézuela/Brésil, 1946, Capitaine Felix Cardona Puig leg. (MNHN). Female, China, Jiangxi W, Jinggang Shan-Ciping, 2/14.VI.1994, E. Jendek \& O. Sausa leg. (NHMW). Female, China, Guangdong, Nanling Ruyuan, stream, 1300 m, 9.V.2004 (24012), P. Grootaert leg., Coll. I.R.Sc.N.B. (IRSN).

Redescription. Male: Body blackish brown (Figs. 1A, B). Head and pronotum subshiny, scutellum and hemelytra pruinose. Total length 8.27.

Head (Fig. 1C) covered with short recumbent and sparse long erect setae dorsally. Clypeus and antenniferous tubercles brown apically. Vertex flattened. Eyes sub-pedunculate (Fig. 1A), not surpassing the dorsal margin of head in lateral view. Ocelli widely set, closer to anterior pronotal margin than to eyes. Bucculae elevated and rounded anteriorly, continued as a low fringe posteriorly. Head length 1.10 , postocular distance 0.05 ; head width across eyes 1.61, interocular space 1.01, interocellar space 0.55. Labium attaining mesosternum; labial segment lengths: I 0.74 , II 0.83, III 0.61, IV 0.62. Antennal lengths: scape 0.84, pedicel 1.73, basiflagellomere 1.56, distiflagellomere missing. Scape brown, rest paler; all with short erect setae. 
Thorax. Collar length at middle 0.17. Pronotum (Figs. 1A, B) with abundant short recumbent setae, and scattered long erect setae. Anterior pronotal length [without collar] 1.68, posterior pronotal length 0.91 ; anterior pronotal lobe width 1.87 , posterior pronotal lobe width 2.30. Scutellum punctate, with abundant short recumbent setae and scattered long erect setae; apex paler. Hemelytra surpassing apex of abdomen; color pattern as on figure 1A. Hind wing with generalized lygaeoid pattern, intervannals fused basally in a U-shape, vannal veins fused basally (Fig. 2). Legs: Coxae, trochanters, profemora except apex, meso- and metafemora except basal $1 / 4$, and tibiae dark brown, rest of legs pale brown. Profemora with abundant erect setae, rest of legs with short recumbent setae; tibiae with spiniform setae. Procoxae with two spines; protrochanters unarmed; profemora incrassate (Fig. 1A), with two rows of strong spines and small spines intermixed between rows; protibiae curved at base (Fig. 1A), with three spines on apical half and two small spines apically. Mesocoxae with a small spine; meso- and metafemora unarmed. Meso- and metatibiae tubular, slightly narrower at base, unarmed. Tarsal article I longer than II and III combined.

Abdomen with abundant short recumbent setae. Abdominal sternites shagreened, finely punctate and pilose. Terga (Fig. 1D): Laterotergites with abundant pilosity. Tergites I and II smooth and shiny, following tergites subshiny, shagreened laterally and transversely rugose medially. Male genitalia: Pygophore (Figs. 3A, B) with posterior margin of dorsal aperture close to posterior margin of pygophore; inner projections broad and extending posteriorly. Parameres as in figures 3C-E. Aedeagus unspined, vesica with four lobes, two anterior short unsclerotized and two large partly sclerotized lobes, helicoidal process forming two coils and gonoporal process thin and long, with six turns (Fig. 3F).

Females measurements (Females from Jiangxi and Guangdong, respectively): Body length: 7.4; 8.15. Head length: $1.35 ; 1.45$, head width $1.55 ; 1.65$, interocular distance $1.0 ; 1.05$, interocellar distance $0.65 ; 0.7$, antennal length: scape $0.65 ; 0.85$, pedicel $1.25 ; 1.35$, basiflagellomere $-; 1.3$, distiflagellomere -; 1.55, labial segments length: I 1.0; 1.05, II 0.85; 0.9, III 0.6; 0.65, IV 0.65; 0.65. Pronotum: collar length $0.1 ; 0.15$, anterior pronotal lobe length (with collar) $1.45 ; 1.55$, anterior pronotal lobe width $1.6 ; 1.75$, posterior pronotal lobe length $0.65 ; 0.8$, posterior pronotal lobe width $1.85,2.1$. Scutellum length $1.25 ; 1.5$. 


\subsection{Species distributional model results and climatic profile}

According to our model (Fig. 4) Scudderocoris albomarginatus, comb. nov., would not find suitable climatic conditions to survive in the region from where the specimen deposited in the MNHN was labeled.

The comparison of the climatic profiles (Figs. 5-6) of the species at its native range and from the Brazilian-Venezuelan frontier leads to the same conclusion. Most of the bioclimatic variables are very different in both areas; boxplots show a high discrepancy with no overlap in the boxes, except for four variables that exhibit a partial overlap (Bio5, Bio8, Bio 10 and Bio18).

Moreover the potential distribution of $S$. albomarginatus comb. nov. strongly aligns with its native range of distribution (Fig. 4); in South America we recovered some small potentially suitable areas on the Andean Region, and others small patches on the Atlantic coast, distant from where the specimen was supposedly collected.

\section{Discussion}

\subsection{Taxonomic discussion}

The generic limits within the tribe Rhyparochromini are in need of revision. Many genera were described based on a different set of characters, therefore a careful study of useful characters to delimit genera in a phylogenetic framework is required. Scudderocoris gen. nov. is close to Caridops, perhaps the most conspicuous difference is the subshiny, coriaceous and very finely punctate anterior lobe of pronotum, which in Caridops is fully smooth and shiny (in $C$. rufescens Zheng, 1981 the lateral part of the pronotum is clearly punctate but shiny and not coriaceous). Both genera can also be distinguished for the following characters: Scudderocoris gen. nov. shows a punctate or very finely wrinkled head, the pronotum has fine recumbent pubescence, the humeral angles are roundly projecting posteriorly, the prosternum is rugose and micropunctate and the abdomen is finely punctate and subshiny, whereas in Caridops the head presents small smooth areas, the pronotum has only long erect setae and the humeral angles in most of the species have at least a rounded (mostly acute) lateral humeral projection without a significant posterior projection, the prosternum is shiny and impunctate, except in the collar region, and the abdomen is partly smooth and shiny, especially on ventral segments III-IV. Scudderocoris gen. nov. also shows similarities with the genus Altomarus Distant, 1903, sharing 
a globose, and a nearly impunctate and laterally ecarinate anterior pronotal lobe, although in Altomarus it is slightly globose and much narrower than the posterior lobe.

\subsection{Biogeographic discussion}

Scudderocoris albomarginatus comb. nov. is known from Japan (between Honshu and Ryukyu Islands), Central and Southern China and South Korea. The finding of this species with a label from South America is intriguing, as the specimen was collected in the mid-20th century in a relatively unexplored area, and this species had not been associated with human activities that could favor its movement around the world. The distribution model of $S$. albomarginatus comb. nov. strongly agrees with its Asian native range, so it would seem that its climatic niche is narrow. Considering all of this evidence and the high discrepancy shown in the climatic profiles of both native distribution and the Brazilian-Venezuelan frontier, we must conclude that the chances of this specimen representing a new distributional record for the species are very low and that the most probable explanation is that it was mislabeled.

\section{Acknowledgements}

We thank Thomas J. Henry (Systematic Entomology Laboratory [SEL], ARS, USDA, c/o National Museum of Natural History, Washington, DC) for the critical reading of the manuscript. This study was supported by the Consejo Nacional de Investigaciones Científicas y Técnicas (CONICET), Argentina, and the following grant: PIP 0249 (2013-2015).

\section{References}

Ashlock, P., Slater, J., 1988. Family Lygaeidae Schilling, 1829, in: Henry, T.J., Froeschner, R.C. (Eds.), Catalog of the Heteroptera, or True Bugs, of Canada and the Continental United States. E. J. Brill, Leiden and New York, pp. 167-245.

Byun, B.-K., Lee, B.-W., Park, S.-Y., Lee, Y.-M., Jo, D.-G., 2009. Insect Fauna of Mt. Nam-san in Seoul, Korea. J. Korean Nature 2(2), 137-153.

Brambila, J., Halbert, S., 2004. First Records for Dieuches armatipes (Rhyparochromidae) in North America. Fla. Entomol. 87(4), 593-596. 
Cassis, G., Gross, G. F., 2002. Hemiptera: Heteroptera (Pentatomomorpha), in: Houston, W.W.K., Wells, A. (Eds.), Zoological Catalogue of Australia vol. 27.3B. CSIRO Publishing, Melbourne, pp. xiv +737 .

Cui, J., Cai, W., Sun, L., Wang, J., 1999. The Fauna and Taxonomy of Insects in Henan (Vol.3)Insects of Jigongshan 3, 57-71. (in Chinese)

Dellapé, P.M., Henry, T.J. Lygaeoidea Species File. Version 5.0/5.0. http://Lygaeoidea.SpeciesFile.org (accessed 13.09.16)

Guisan, A., Thuiller, W., 2005. Predicting species distribution: offering more than simple habitat models. Ecol. Lett. 8(9), 993-1009.

Hayashi, M. 2002, Heteroptera, in: Azuma, S., Yafuso, M., Kinjo, M., Hayashi, M., Kohama, T., Sasaki, T., Kimura, M., Wakamura, F. (Eds.), Check list of the insects of the Ryukyu Islands. 2nd Edition. Biol. Soc. Okinawa, Nishihara, pp. 125-149. (in Japanese)

Henry, T.J., 1997. Phylogenetic analysis of family groups with the infraorder Pentatomomorpha (Hemiptera: Heteroptera), with emphasis on the Lygaeoidea. Ann. Entomol. Soc. Am. 90, 275301.

Henry, T.J., Froeschner, R.C., 1993. Dieuches armatipes (Walker) (Heteroptera: Lygaeidae) newly discovered in the Western Hemisphere. Proc. Entomol. Soc. Wash. 95, 449-452.

Henry, T.J., Dellapé, P.M., Silva de Paula, A., 2015. The Big-Eyed Bugs, Chinch Bugs, and Seed Bugs (Lygaeoidea), in: Panizzi, A., Grazia, J. (Eds.), True Bugs (Heteroptera) of the Neotropics. Springer publishing Co., England and USA, pp. 459-514.

Hong, E.-J., Jeon, Y.-L., Yoon, J.-C., Kim, J.-Y., Lee, M.-H., Kim, J.-W., Park, S.-J., Kim, K.G., Kim, J.-H., Kim, B.-J., 2012. Insect Diversity of Mt. Oseosan. J. Korean Nature 5(3), 251-266.

Lim, J.-S., Park, S.-Y., Lim, J.-O., Lee, B.-W., 2013. A Faunastic [sic] Study of insects from Is. Ulleungdo and its nearby islands in South Korea. J. Korean Nature 6(1), 93-121.

Miyamoto, S., 1970. Heteroptera of Tsushima (1). Pentatomomorpha. Mem. Natl. Sci. Mus. 3, 251-267. (in Japanese)

Phillips, S.J., Anderson, R.P., Schapire, R.E., 2006. Maximum entropy modeling of species geographic distributions. Ecol. Model. 190, 231-259.

Radosavljevic, A., Anderson, R.P., 2014. Making better MAXENT models of species distributions: complexity, over fitting and evaluation. J. Biogeogr. 41, 629-43. 
Raes, N., Ter Steege, H., 2007. A null model for significance testing of presence only species distribution models. Ecography 30, 727-736.

Scott, J., 1874. On a collection of Hemiptera- Heteroptera from Japan. Description of various new genera and species. Ann. Mag. nat. Hist. series 4, 14, 289-304, 350-365, 426-452.

Slater, J.A., 1964. A Catalogue of the Lygaeidae of the World. 2 Vols. Univ. Connecticut, Storrs, USA, 1668 pp.

Slater, J.A., 1972. The occurrence of Elasmolomus sordidus (F.), a potential pest of peanuts, in Brazil (Hemiptera: Lygaeidae). O Biológico 38, 394-395.

Slater, J.A., Hurlbutt, H.W. 1957. A comparative study of the metathoracic wing in the family Lygaeidae. Proc. Ent. Soc. Wash. 59, 67-79.

Slater, J.A., Lattin, J.D., 1965. Lachnestes singalensis (Dohrn), a lygaeid new to the Western Hemisphere (Hemiptera). Pan-Pacific Entomol. 41, 58-60.

Zheng, L.Y., Zou, H.G., 1981. Lygaeidae, in: Hsiao, T.Y. (Ed.), A handbook for the identification for the Chinese Hemiptera- Heteroptera. Science Press, Peking, pp. 1-214. (in Chinese)

Figure captions

Fig. 1. Scudderocoris albomarginatus gen. nov., comb. nov. (A) Dorsal view. (B) Lateral view. (C) Head, lateral view. (D) Abdomen, dorsal view.

Fig. 2. Scudderocoris albomarginatus gen. nov., comb. nov. Hind wing venation. C: cubitus, M: medius, R: radius, V: vannals, IV: intervannals.

Fig. 3. Scudderocoris albomarginatus gen. nov., comb. nov. Male genitalia. (A) Pygophore, dorsal view. (B) Pygophore, lateral view. (C) Paramere, inner view. (D) Paramere, outer view. (E) Paramere, lateral view. (F) Aedeagus, posterior view.

Fig. 4. Scudderocoris albomarginatus gen. nov., comb. nov. Presence binary areas of its SDM. (A) In Asia, red dots are the native records of the species. (B) In South America, red fringe indicate the area from where we extracted the climate data to build the boxplots for South America.

Fig. 5. Boxplots of the climatic variables of the known distribution of $S$. albomarginatus gen. nov., comb. nov., and from the area in the Brazilian-Venezuelan frontier. Temperature-related variables (Bio1- 11). 
Fig. 6. Boxplots of the climatic variables of the known distribution of $S$. albomarginatus gen. nov., comb. nov., and from the area in the Brazilian-Venezuelan frontier. Precipitation-related variables (Bio12- 19). 


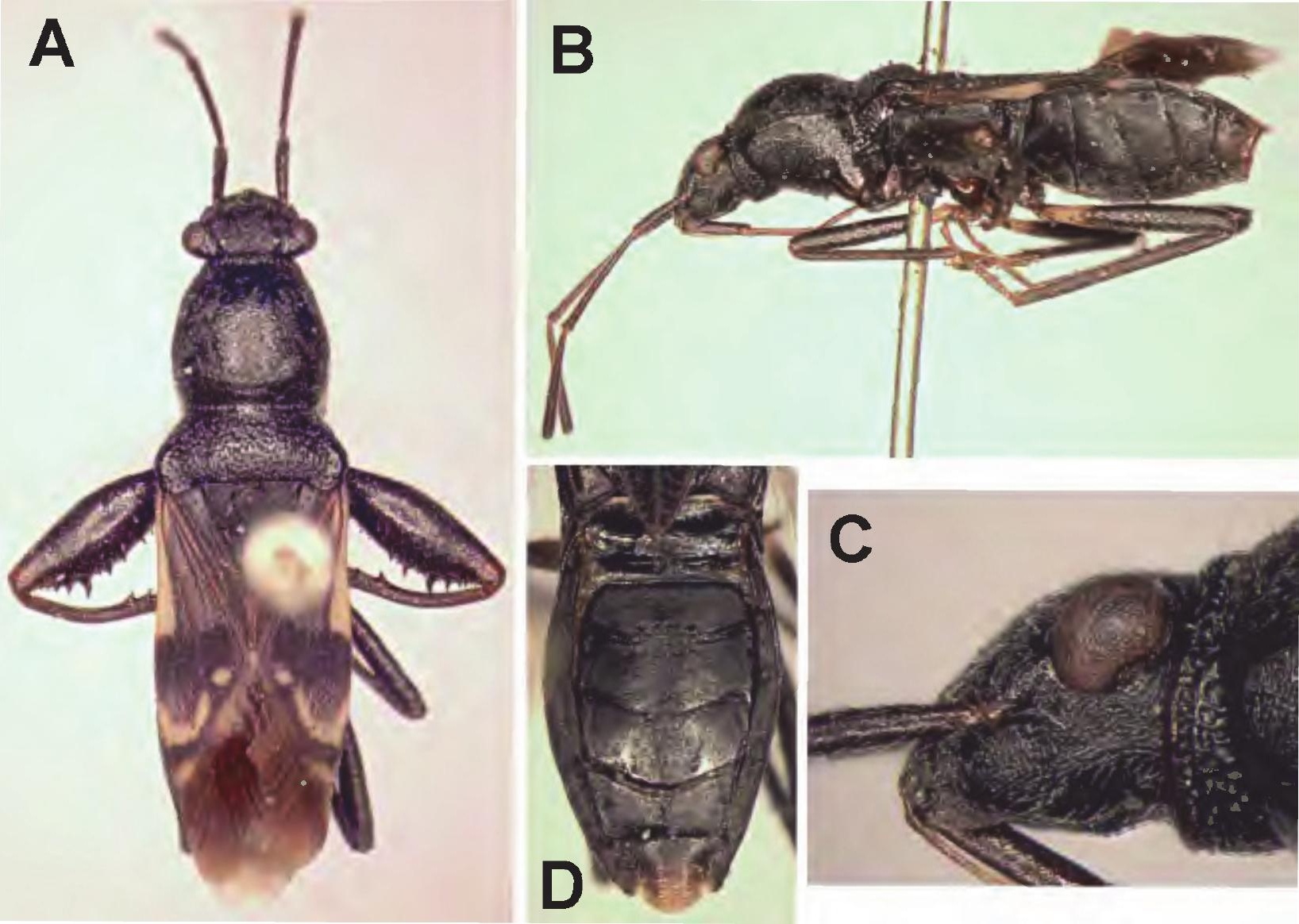




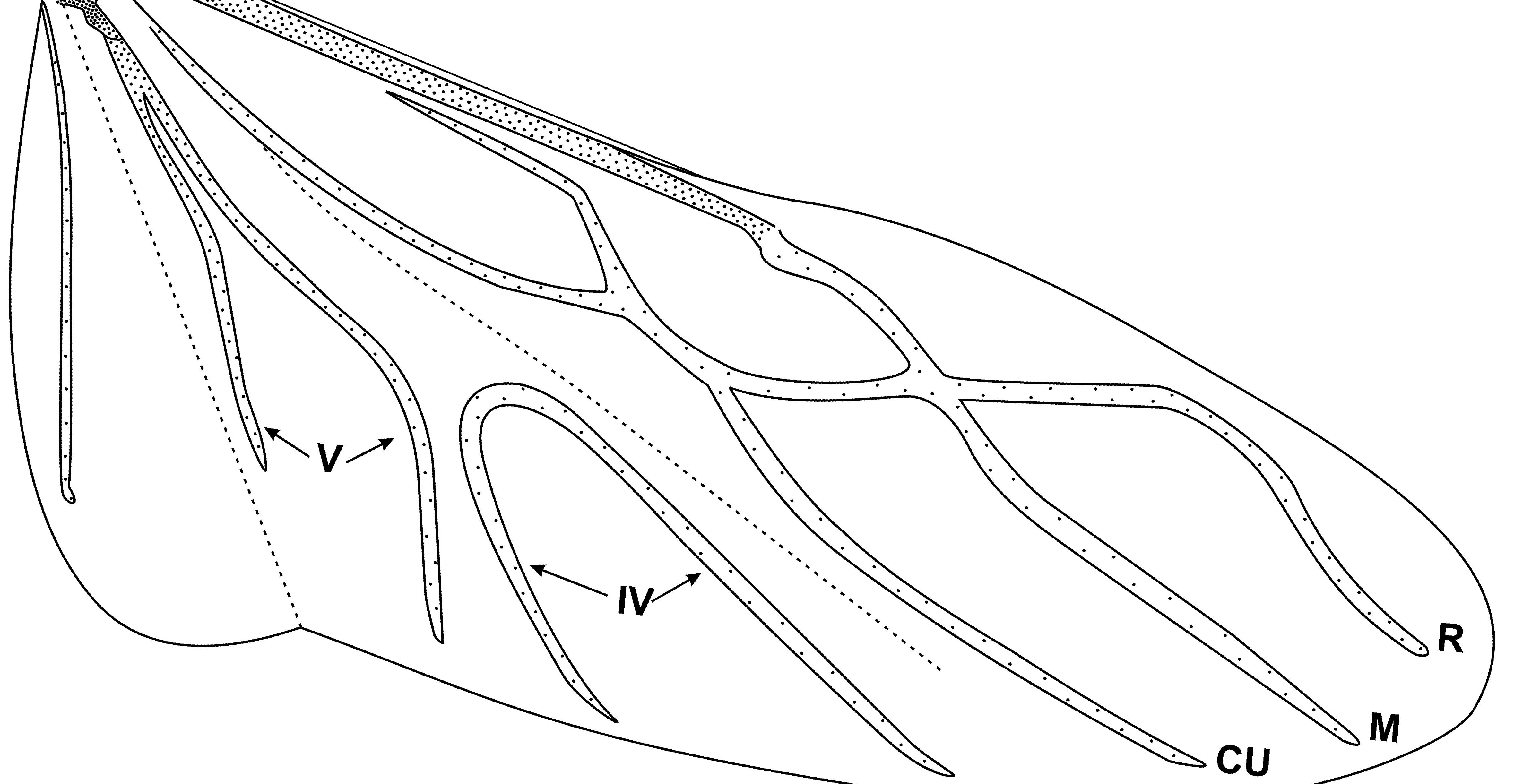




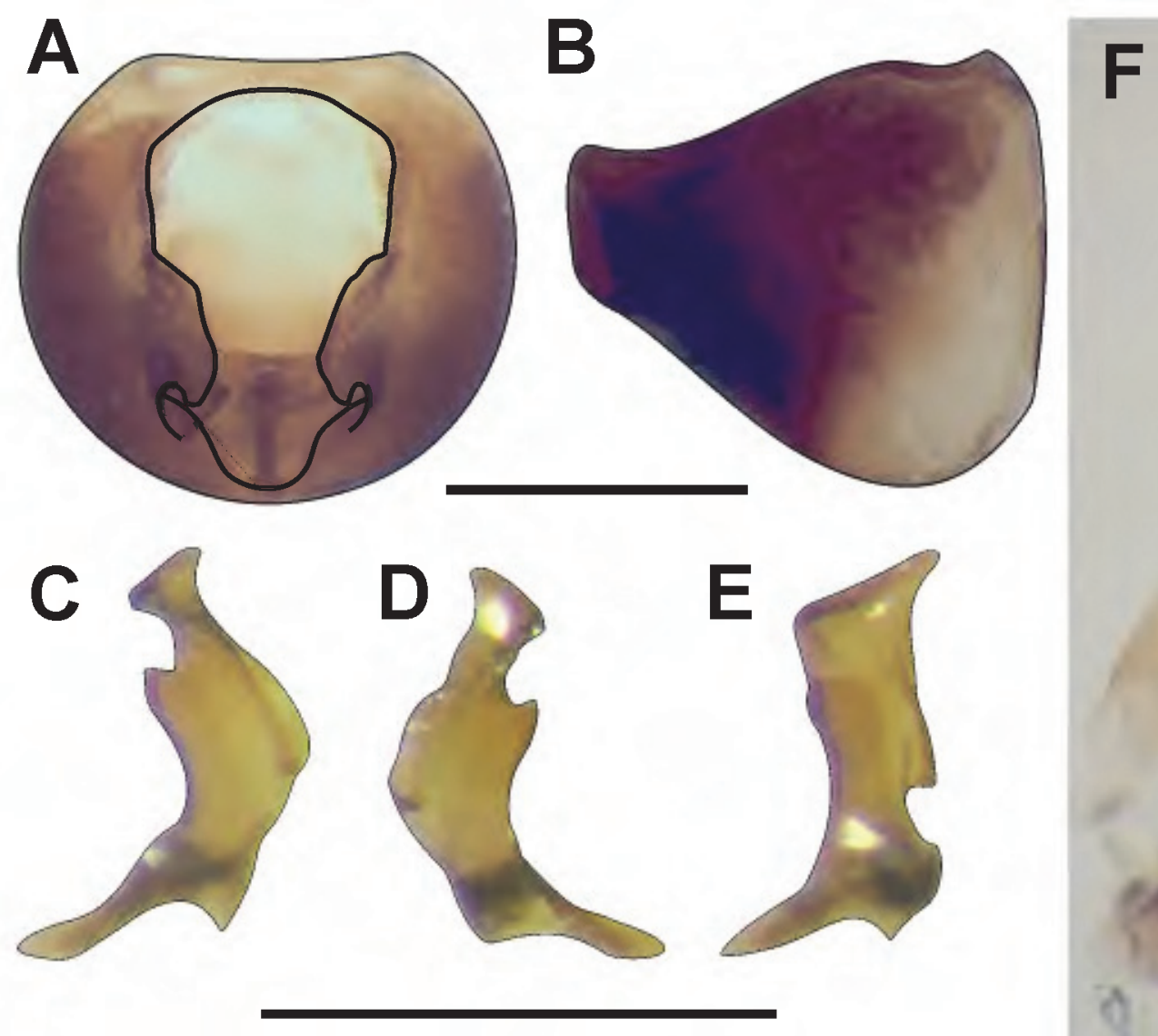




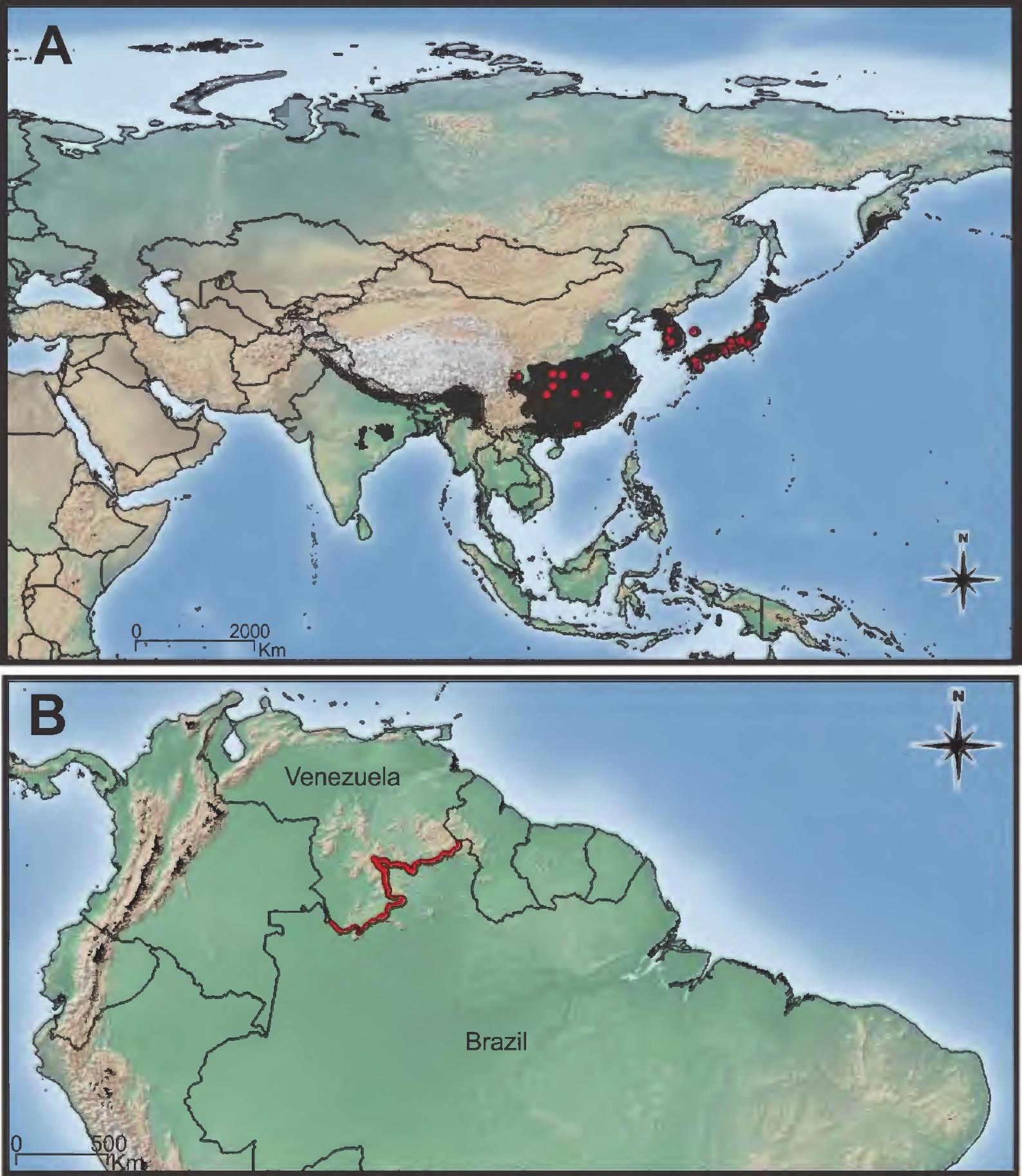




\section{BlO1 = Annual mean temp.}
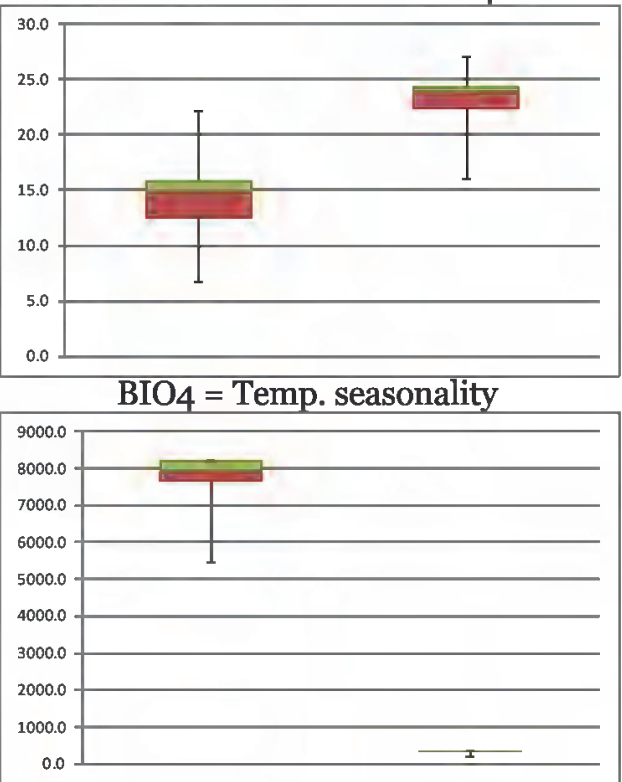

\section{$\mathrm{BIO7}=$ Temp. annual range}

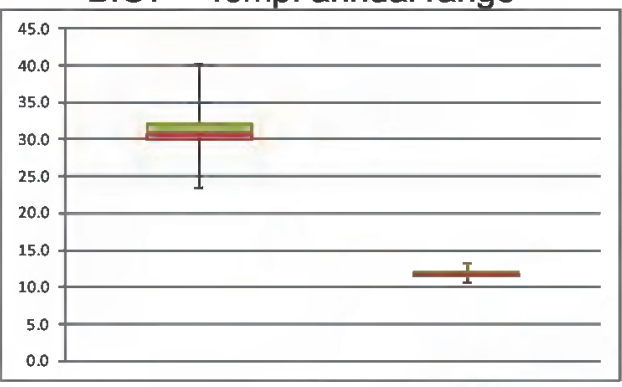

$\mathrm{BIO10}=$ Mean temp. of warmest quarter

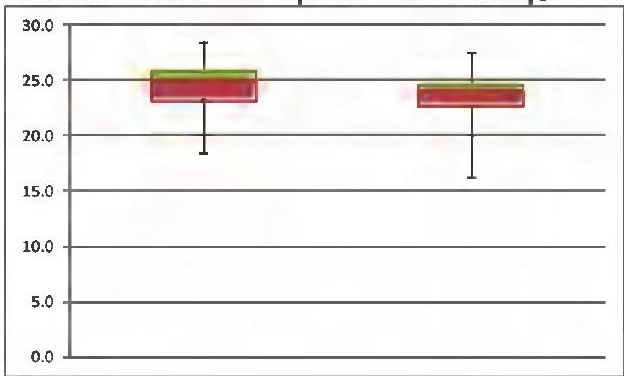

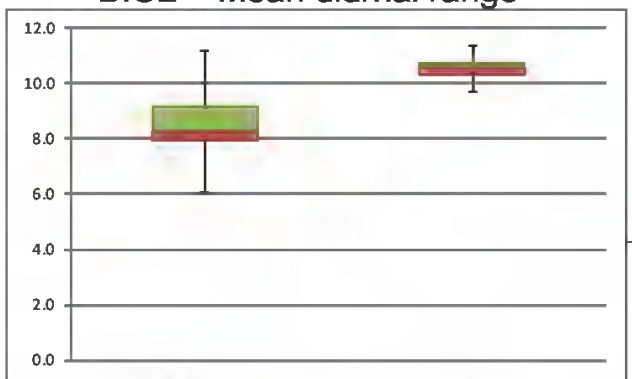
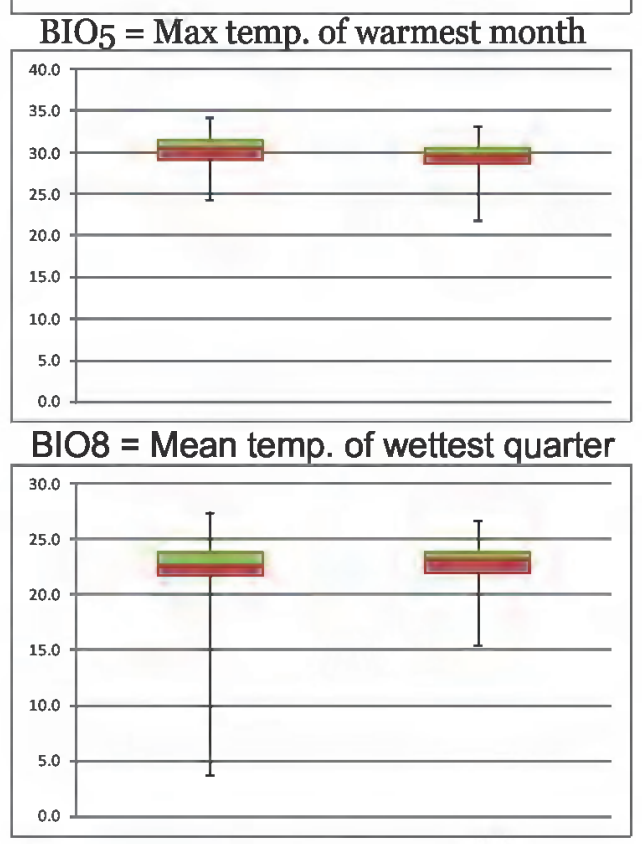

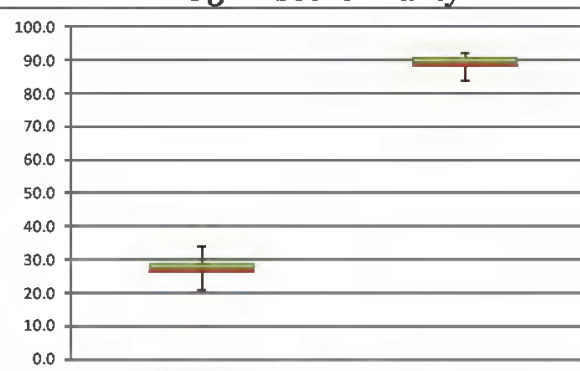

BIO6 = Min temp. of coldest month

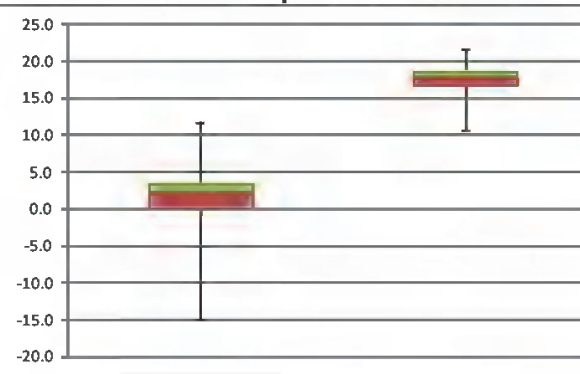

$\mathrm{BIO9}=$ Mean temp. of driest quarter

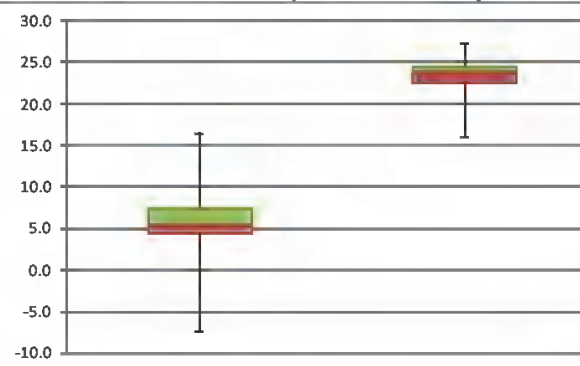

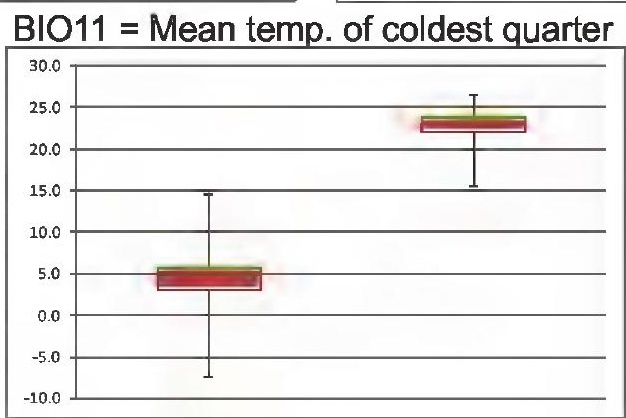


